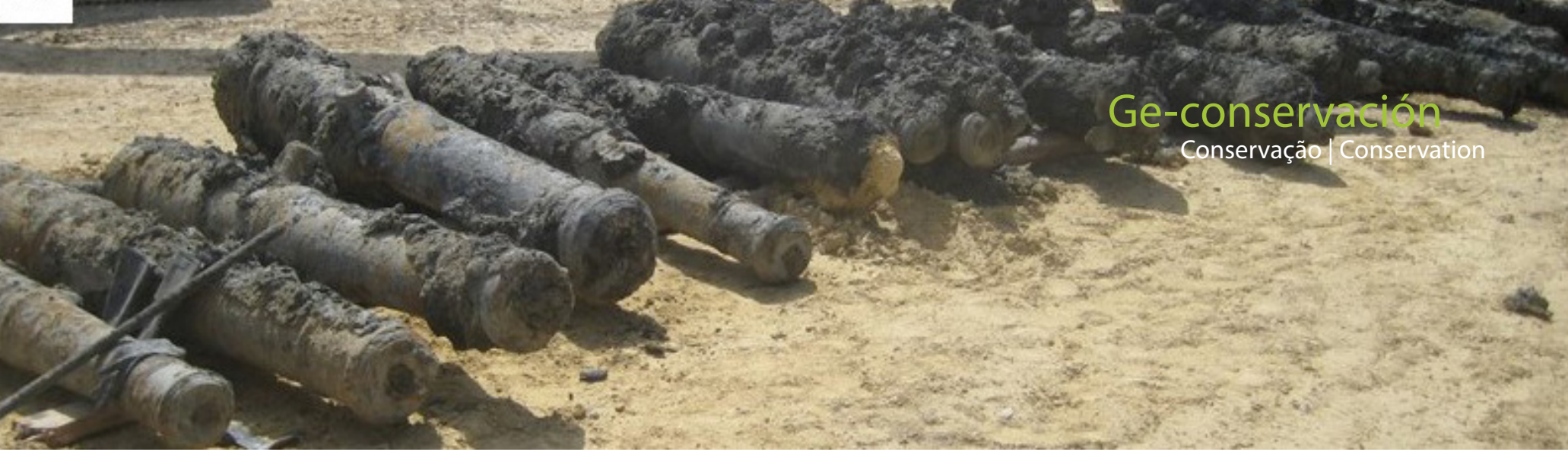

\title{
Tratamiento de conservación a gran escala de piezas de artillería pesada de hierro fundido y procedencia subacuática. Procedimientos metodológicos
}

\author{
Inmaculada Sánchez Pedreño, Ignacio Salas Pardo de Donlebún, Juan Francisco García Amado, \\ Santos García Trigo, Manuel Bethencourt Núñez
}

\begin{abstract}
Resumen: Este trabajo describe el tratamiento simultáneo de limpieza y extracción de iones cloruro, mediante electrolisis, de 17 cañones de hierro del siglo XVIII, de origen subacuático, procedentes de un hallazgo casual. En un contexto de bajo presupuesto, se desarrollaron cubas a medida y herramientas específicas para la desconcreción de las piezas: una barrena de alta precisión para acceder al ánima de los cañones y bases de trabajo giratorias. Además, se aplicó una nueva técnica de estabilización para piezas grandes de fundición mediante envolturas en material absorbente impregnado en $\mathrm{NaOH}$. La selección de la densidad de corriente para los tratamientos de electrolisis se estableció mediante un ensayo previo, que demostró la mayor eficiencia de $50 \mu \mathrm{Acm}^{-2}$ frente a 1000 $\mu \mathrm{Acm}^{-2}$. La descripción de las tareas realizadas, junto con las novedades metodológicas aportadas, conforman una valiosa información para futuras actuaciones en materia de conservación a gran escala del Patrimonio Cultural Subacuático (PCS).
\end{abstract}

Palabras clave: cañones de hierro, tratamiento electrolítico simultáneo, desarrollo de herramientas, extracción de cloruros

\section{Large-scale conservation treatment of cast-iron heavy artillery pieces from underwater origin. Methodological procedures}

Abstract: This paper describes the simultaneous cleaning and chloride extraction, through electrolysis treatment, of 17 underwater-origin cast iron barrels from XVIII century coming from a casual find. Within a low-budget context, customized vats were made. Specific tools for the cleaning of the pieces were also developed: a high-precision drill to access the bore of the barrels and rotating work bases. Moreover, a new stabilization technique for large casting pieces was applied by wrapping them in absorbent material impregnated in $\mathrm{NaOH}$. The selection of the current density for the electrolysis treatment was established by a previous test, which demonstrated the higher efficiency of $50 \mathrm{\mu Acm}^{-2}$ against $1000 \mu \mathrm{Acm}^{-2}$. The description of the tasks performed, along with the novel methodological procedures provided, constitute a valuable information for future actions in the field of large-scale conservation of Underwater Cultural Heritage (UCH).

Keywords: iron barrels, simultaneous electrolysis treatment, tools development, chlorides extraction

\section{Tratamento de conservação a grande escala de peças de artilharia pesada de ferro fundido e procedencia subaquatica. Procedimentos metodológicos}

Resumo: Este trabalho descreve o tratamento simultâneo de limpeza e extração de iões cloreto, mediante eletrólise, de 17 canhões de ferro do século XVIII, de origem subaquática, procedentes de um achado casual. Num contexto de baixo orçamento, foram desenvolvidas cubas sob medida e ferramentas específicas para a desconcreção das peças: uma broca de alta precisão para aceder ao interior dos canhões e bases de trabalho giratórias. Além disso, aplicou-se uma nova técnica de estabilização para peças grandes de fundição através da cobertura destas em material absorvente impregnado em $\mathrm{NaOH}$. A selecção da densidade da corrente para os tratamentos de eletrólise foi estabelecida através de um ensaio prévio, que demonstrou a maior eficiência de $50 \mu \mathrm{Acm}^{-2}$ em relação a $1000 \mu \mathrm{Acm}{ }^{-2}$. A descrição das tarefas realizadas, juntamente com as novidades metodológicas encontradas, formam uma valiosa informação para futuras ações em matéria de conservação em grande escala do Patrimonio Cultural Subaquático (PCS).

Palavras-chave: canhões de ferro, tratamento eletrolítico simultâneo, desenvolvimento de ferramentas, extração de cloretos 


\section{Antecedentes}

El Patrimonio Cultural Subacuático (PCS) desvela información básica de las distintas etapas históricas en áreas muy diversas del conocimiento, no solo sobre aspectos puramente técnicos como la construcción naval, sino también sobre cuestiones como la organización y el desarrollo económico de las sociedades. Siguiendo los principios generales de la UNESCO aceptados en la Convención de París sobre la Protección del Patrimonio Cultural Subacuático en 2001, la preservación in situ debe considerarse la primera opción antes de emprender cualquier actividad dirigida al PCS. Sin embargo, con frecuencia tienen lugar actuaciones que contradicen dicho principio. Al margen de la extracción controlada de piezas con fines científicos en yacimientos catalogados, son comunes los hallazgos casuales en obras de naturaleza civil, donde la extracción de las piezas del lugar de la excavación resulta imperativa por cuestiones tanto de interés público, como políticas o presupuestarias. Cuando el hallazgo comprende piezas de gran tamaño de procedencia subacuática, los tratamientos de conservación sobre las mismas se dificultan exponencialmente debido, entre otros, a la complejidad de la manipulación y a los factores de deterioro extrínsecos propios del medio marino. Así, en la mayoría de hallazgos de piezas de estas características, las actuaciones dirigidas a su conservación se simplifican y acaban por ser insuficientes: la recuperación y puesta en valor de 16 cañones del siglo XVIII, en las murallas de Cádiz (Ramos Gil 2015), o los trabajos realizados sobre los cañones de la ciudad de San Francisco de Campeche en Méjico (Arano 2009), constituyen ejemplos en los que los tratamientos realizados para la conservación de las piezas no incluyeron la extracción de iones cloruro $\left(\mathrm{Cl}^{-}\right)$. En otras ocasiones se busca una solución de compromiso, consistente en volver a integrar los elementos metálicos en el medio marino. Así, en 2015, un conjunto de 28 piezas de artillería y 7 anclas pertenecientes a los pecios Delta I y Delta II, localizadas en las obras de ampliación del puerto de contenedores de Cádiz, fueron re-depositadas en el mar tras varios meses de espera en tanques de almacenamiento en tierra firme (comunicación personal). En todo caso, las actuaciones reflejadas en la bibliografía existente no muestran como una práctica común la extracción de iones cloruro en grupos de piezas metálicas de gran calibre.

La alta concentración de $\mathrm{Cl}^{-}$presente en piezas metálicas, procedentes del medio marino, es directamente responsable de su deterioro mediante un proceso local de acidificación conocido como corrosión activa (Wang 2007, Watkinson, AlZahrani 2008). Por ello, la conservación a largo plazo de piezas de esta naturaleza está directamente ligada a la extracción de estos iones. Aunque en objetos de hierro se ha demostrado que la simple inmersión en disoluciones alcalinas permite su eliminación (Selwyn 2004, Scmutzler y Ebinger-Rist 2008), diversos autores han demostrado en las últimas décadas que la técnica de electrolisis, utilizada desde mediados del siglo XX (Plenderleith 1956), constituyeun tratamiento de conservación más adecuado para piezas metálicas de procedencia subacuática (Doménech-Carbó et al. 2009, Coelho 2010, Degrigny 2010, Bethencourt y Zambrano 2011). Sin embargo, la ejecución simultánea de esta técnica en piezas metálicas de gran envergadura requiere de grandes infraestructuras y una inversión económica considerable. Como muestra de esta dificultad, cabe mencionar trabajos homólogos realizados actualmente en España por tres de los centros de referencia en materia de restauración de arqueología subacuática. Así, el laboratorio del Centro de Arqueología Subacuática de Andalucía (CAS) dispone de cubas de electrolisis de diferentes tamaños y realiza tratamientos de estabilización catódica, si bien no suele abordar tratamientos de manera simultánea a piezas de gran tamaño. Algo similar ocurre en el Museo Nacional de Arqueología Subacuática (ARQUA), cuyo laboratorio ha realizado recientemente la extracción de $\mathrm{Cl}^{-}$a dos culebrinas de bronce procedentes de la Fragata Mercedes (http://www.culturaydeporte.gob.es/mnarqua/ investigacion/proyectos/nsm.html). En cuanto al Laboratorio de Estudios y Conservación del Patrimonio Histórico (LECPH) de la Universidad de Cádiz, aunque dispone de cubas donde realizar trabajos de estabilización, estas no pueden, por limitaciones de tamaño, acoger objetos superiores a 150 $\mathrm{cm}$. Tales circunstancias, unido a la inexistencia de trabajos publicados hasta la fecha sobre tratamientos simultáneos que pudiesen ser comparables atendiendo a la metodología, número y tamaño de piezas, dan idea de la dimensión del desafío planteado en este trabajo.

El objetivo de este trabajo es describir el conjunto de actuaciones de bajo coste llevadas a cabo para concluir, en un breve espacio de tiempo y de manera simultánea, los tratamientos de urgencia requeridos para la conservación de 17 cañones de hierro fundido de procedencia subacuática, extraídos tras un hallazgo casual. Para ello, mediante el uso de materiales comúnmente usados en otras disciplinas profesionales, se desarrollaron métodos y herramientas específicas que agilizaron y facilitaron los trabajos de limpieza, desconcreción y estabilización de las piezas. Además, los parámetros del tratamiento electrolítico se establecieron mediante un ensayo comparativo previo realizado sobre dos balas de cañón procedentes del mismo hallazgo. La información contenida en este trabajo puede resultar especialmente valiosa para acometer futuros trabajos de conservación a gran escala de grandes objetos metálicos de difícil manipulación, provenientes de yacimientos o hallazgos no planificados, que no cuenten con las infraestructuras y medios económicos suficientes.

\section{Contexto arqueológico de las piezas y metodología aplicada}

\section{—Hallazgo de las piezas}

En el año 2009, fueron halladas en el entramado defensivo relacionado con la Batería del Caballero Zuazo, San Fernando (Cádiz), [Figura 1A], 19 piezas arqueológicas presumiblemente del s. XVIII sumergidas en fango de la zona intermareal de un caño de marea. Durante las obras de excavación para el acondicionamiento de las infraestructuras del tranvía metropolitano Bahía de Cádiz, 
se extrajeron 17 cañones de hierro fundido con ánimas de entre 7 y $13 \mathrm{~cm}$, longitudes de entre 2,08 y 2,73 m y pesos finales, una vez limpios, de entre 647 y 1.918 kg, así como dos balas de cañón de 10,50 y 10,95kg, ambas de calibre 32 .

Extraídas el 7 de septiembre [Figuras 1B, 1Cy 1D], a su llegada al laboratorio, tres meses más tarde, las piezas presentaban un avanzado proceso de corrosión debido a la ausencia de actuaciones de conservación a pie de obra. A instancia del Ministerio de Obras Públicas, la empresa Aula3 AIP S.L. aceptó el reto de realizar los correspondientes trabajos de conservación y restauración, que incluían entre sus fases la estabilización del metal y la extracción de cloruros mediante electrolisis. Reunido un equipo multidisciplinar compuesto por arqueólogos, restauradores e ingenieros, se habilitó un laboratorio de restauración específicamente diseñado para dar acogida a las 17 piezas metálicas de gran envergadura, que recibirían, de forma simultánea, el tratamiento electrolítico necesario para su conservación; una actuación sin precedentes que tuvo una duración de un año.

\section{- Organización del espacio}

Los trabajos tuvieron lugar en una nave industrial de $1000 \mathrm{~m}^{2}$ de superficie total, ubicada en el polígono Fadrícas, en San Fernando (Cádiz). Se acondicionaron $950 \mathrm{~m}^{2}$ de superficie diáfana como laboratorio húmedo. Dicho laboratorio fue equipado con puente grúa, cubas de inmersión para tratamiento electrolítico, fuentes de alimentación regularmente distribuidas [Figuras 2A, 2B y $2 C$ ], un desionizador de agua, un sistema portátil de aspiración de líquidos y mangueras de diferentes diámetros. En esta misma área, mediante el uso de una carpa portátil, se aisló un espacio destinado a la desconcreción de las piezas [Figura 2E], el cual fue dotado con martillos, cinceles y micro-cinceles, así como con herramientas específicamente fabricadas. El resto de la superficie lo compusieron espacios independientes, destacando el laboratorio seco de análisis de muestras [Figura 2D], que fue equipado con un medidor portátil de $\mathrm{pH}$ y temperatura, un electrodo de referencia de $\mathrm{Ag} / \mathrm{AgCl}$ y un multímetro digital. La cantidad de iones cloruro eliminados fue monitorizada por métodos clásicos de valoración (Wang 2007, Burshneva y Smirnova 2010). Técnicas más ágiles para este propósito, como la cromatografía iónica (Coelho et al. 2014), no estaban disponibles en el año 2009.

-Estabilización inicial y desconcreción de las piezas. Fabricación de cubas a medida y desarrollo de herramientas específicas

La primera actuación realizada en el laboratorio fue la estabilización inicial de las piezas, la cual se realizó mediante su inmersión en una disolución acuosa de $\mathrm{NaOH} 5 \mathrm{M}, \mathrm{pH}$ $13,3 \pm 0,6$ y a temperatura ambiente. Utilizando materiales comúnmente empleados en otras áreas profesionales se diseñaron cubas de bajo coste a la medida de cada cañón; con este objetivo, se construyeron armazones rectangulares con listones de madera de pino y paneles de tablero marino reforzados en su parte superior e inferior. Posteriormente se introdujo una capa impermeable de polietileno de baja densidad, de 1200 galgas de espesor, a modo de "bolsa"
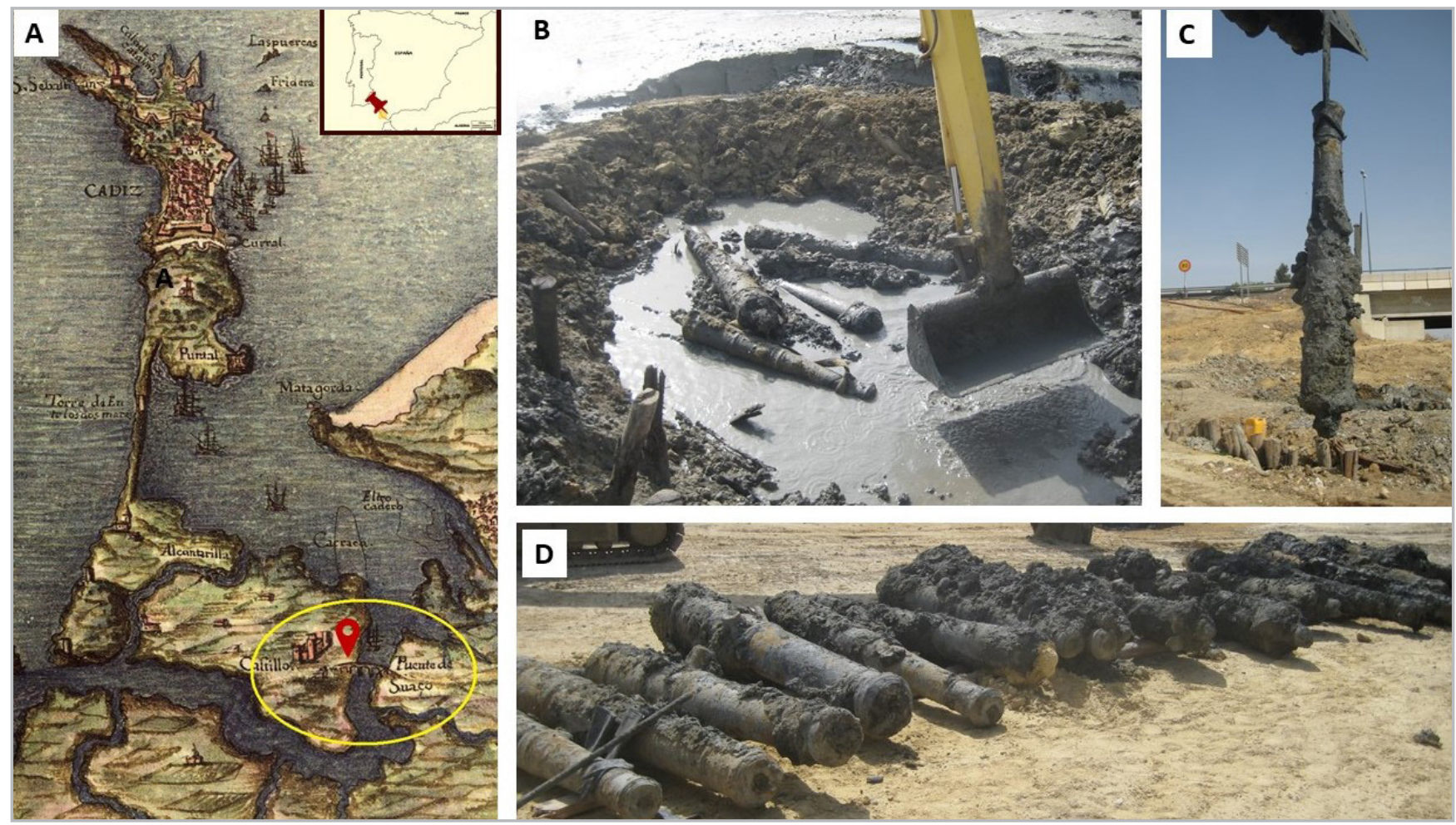

Figura 1.- Localización del hallazgo sobre un plano de la Bahía de Cádiz del s. XVIII (A). Extracción de las piezas (B, C y D). Fotografías de la Agencia de Obras Públicas de la Junta de Andalucía. Consejería de fomento, Infraestructuras y Ordenación del Territorio. 


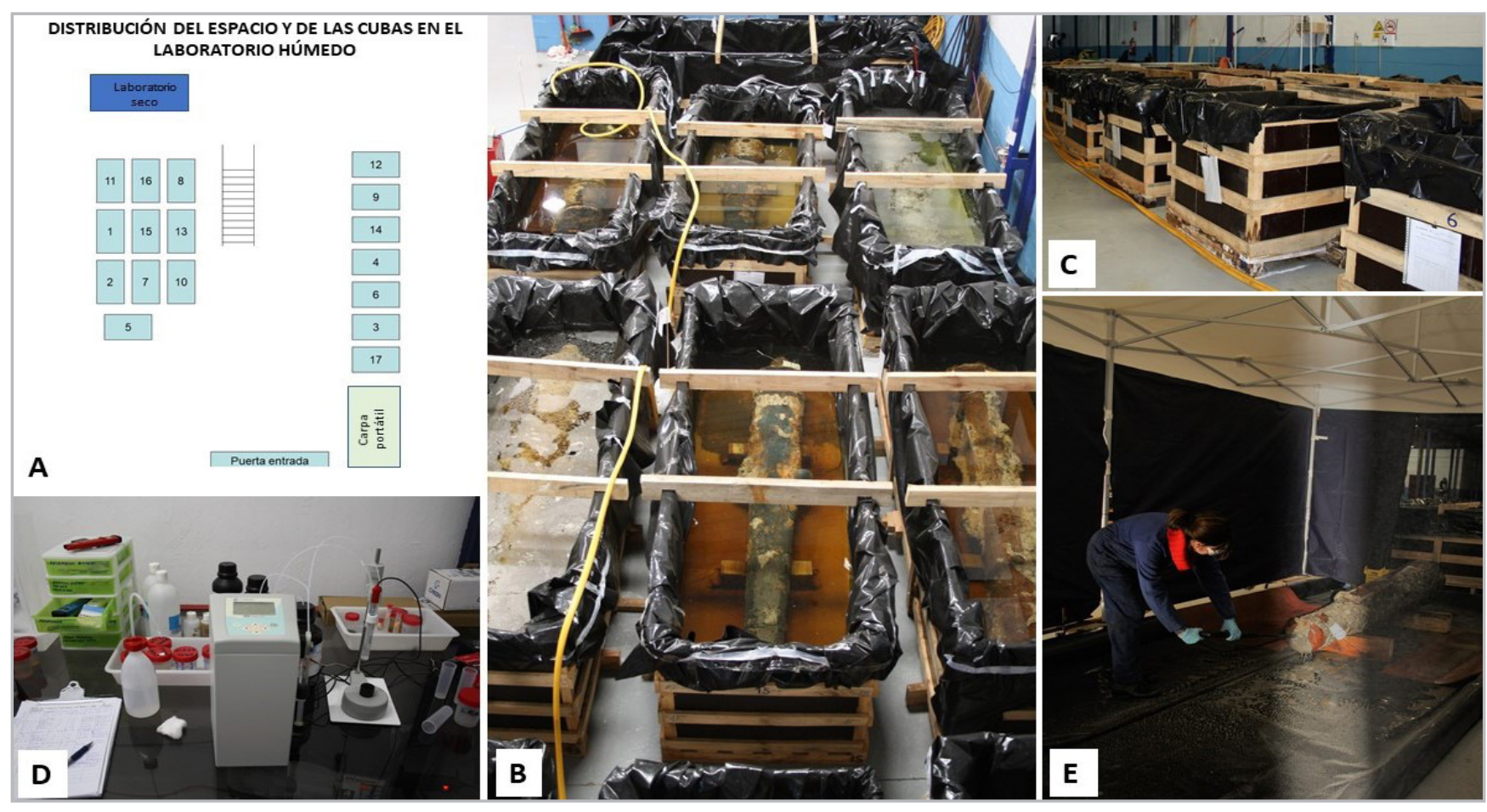

Figura 2.- Distribución del espacio y de las cubas con cañones sumergidos en disolución de $\mathrm{NaOH} 5 \mathrm{M}$, dentro del laboratorio húmedo (A, B y C). Laboratorio seco (D). Espacio delimitado con carpa portátil (E). Fotografías de archivo de Aula3 AIP S.L.

[Figuras 2B y 2C]. Por último, se tallaron a medida, igualmente en madera de pino, piezas de apoyo para los cañones.

La fase de desconcreción se realizó fuera de las cubas, utilizando agua a presión, martillos y cinceles para las capas más gruesas de concreción, y micro-cinceles de aire comprimido para las intervenciones de mayor precisión. Vista la dificultad de manipulación de las piezas, debido a su envergadura, peso y fragilidad, se diseñaron unas bases de trabajo giratorias [Figura 3] constituidas por dos estructuras metálicas de $70 \mathrm{~cm}$ de alto con forma de prisma de base rectangular. En la parte superior se colocaron dos
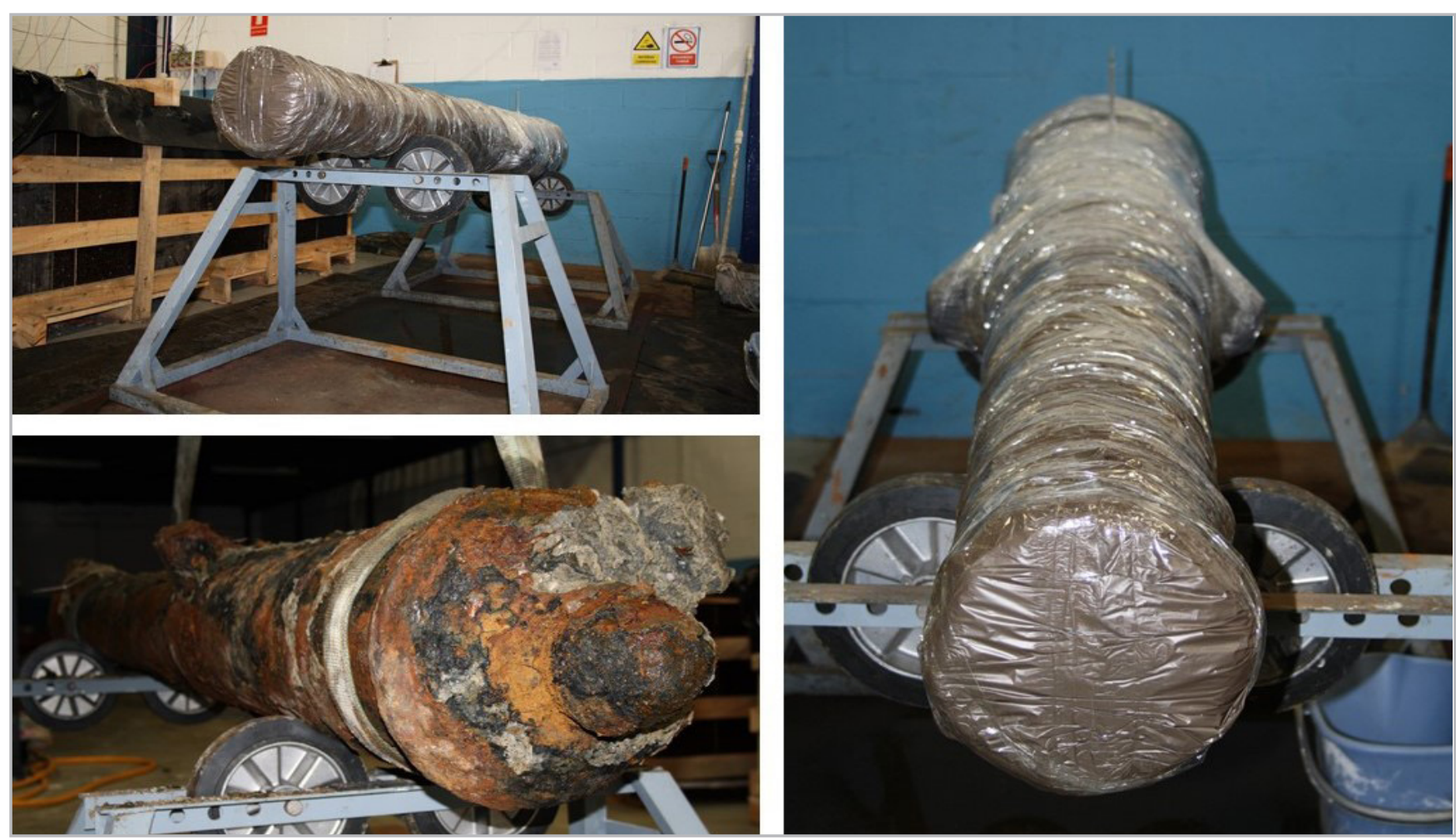

Figura 3.- Bases de trabajo giratorias ( $A, B$ y C). Ensayo de técnica de estabilización para piezas de gran calibre (A y C). Fotografías de archivo de Aula3 AIP S.L. 
ruedas de caucho elástico natural con gran capacidad de carga. Además, varias perforaciones realizadas en los listones superiores de cada base permitían unir o separar las ruedas a conveniencia, haciendo de nuestras bases soportes adecuados para todas las piezas a tratar, independientemente de su tamaño.

Paralelamente, se desarrolló una barrena portátil de alta precisión para la limpieza de las ánimas de los cañones, apta para cualquier modelo, longitud y diámetro de cañón [Figura 4]. Esta fue fabricada a partir de un perforador de base (usado en todo momento con $460 \mathrm{rpm}$ ), un gato elevador de vehículos y una estructura metálica sencilla. Disponía de una toma de agua para evitar el calentamiento debido a la fricción de la corona con el metal, facilitando al tiempo la evacuación de los restos. Por último, para minimizar la posibilidad de daños en el ánima durante el procedimiento, se acopló un sistema láser que permitió una alineación perfecta del ánima con las coronas de perforación, fabricadas en $7,8,9,10,11,11,5,12,5$ y 13 $\mathrm{cm}$ de diámetro, conforme a los distintos diámetros de las ánimas de los cañones.

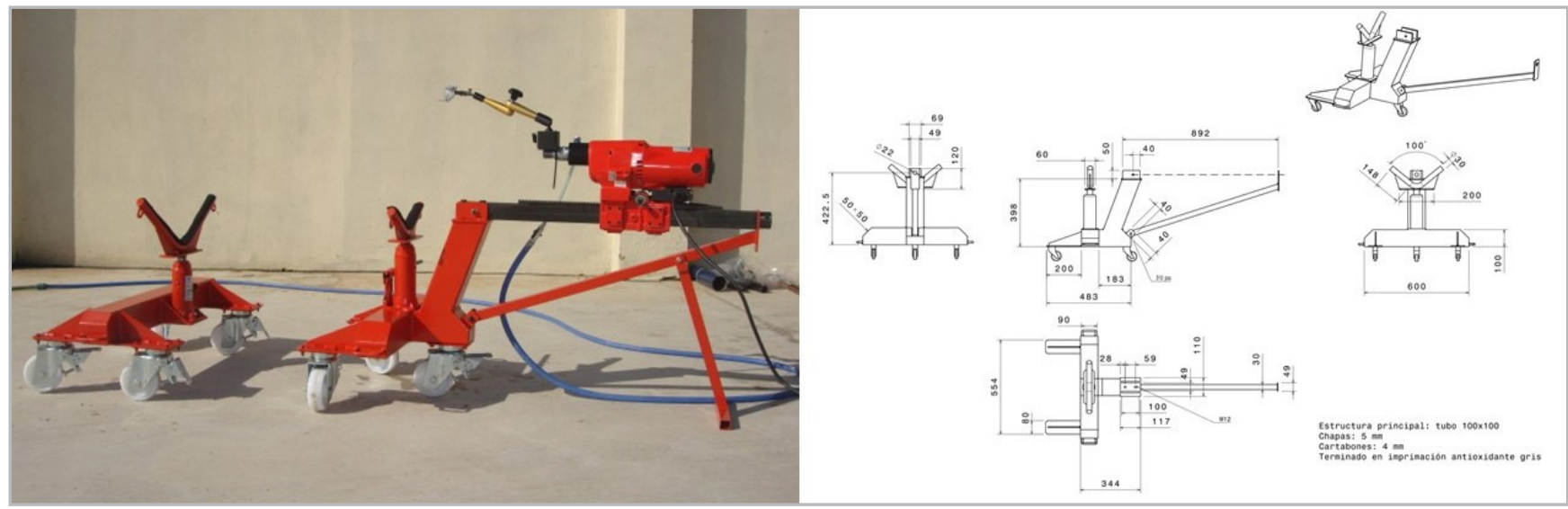

Figura 4.- Barrena de alta precisión (izquierda). Plano parcial del diseño original del sistema realizado por J. F. García Amado e lgnacio Salas Pardo (derecha). Fotografías de archivo de Aula3 AIP S.L.

\section{- Estabilización de urgencia para piezas de gran calibre}

A fin de evitar procesos de degradación propios de piezas extraídas de un medio húmedo a una atmósfera seca y oxigenada (Rimmer et al 2013), se desarrolló un modelo de estabilización de urgencia para piezas de gran calibre. Dicha técnica realizada a la temperatura ambiente del interior de la nave $\left(15-26^{\circ} \mathrm{C}\right)$ se basó en un sistema de doble envoltura de la pieza, siendo la primera de ellas realizada con una bobina de trapo de algodón empapada en una disolución de $\mathrm{NaOH} 5 \mathrm{M}$ en agua corriente. El alto poder de absorción de este tejido, compuesto por un $80 \%$ de algodón, resultó óptimo para mantener la pieza húmeda. A su vez, dicha envoltura fue cubierta mediante una película plástica transparente, comúnmente utilizada como producto de embalaje. Por último, como medida de seguridad, el conjunto fue sellado con cinta de embalaje adhesiva de PVC, generando así la estanqueidad suficiente para mantener, temporalmente, la humedad de las piezas [Figuras $3 \mathrm{~A}$ y $3 \mathrm{C}$ ].

\section{- Optimización de la densidad de corriente para el trata- miento electrolítico}

Con el propósito de obtener datos útiles para del tratamiento de extracción de $\mathrm{Cl}^{-}$que se aplicaría posteriormente a los cañones, se realizó un ensayo previo con dos balas de cañón de hierro procedentes del mismo hallazgo. Hamilton (1997) recomienda densidades de corriente distintas en función de si se pretende una pasivación, una extracción de cloruros o una limpieza mecánica de la superficie de la pieza. Por su parte, Bertholon (2001) empleó densidades de corriente de hasta $1050 \mu \mathrm{A} \cdot \mathrm{cm}^{-2}$ en tratamientos utilizados para la estabilización de piezas de hierro fundido de procedencia subacuática. A su vez, en 2001, se demuestra una mayor eficiencia en la extracción de cloruros en piezas de hierro forjado aplicando una densidad de corriente de $50 \mu \mathrm{Acm}^{-2}$ (Carlin et al. 2001). En una bala similar a las consideradas en este trabajo, Gil et al. (2003) aplicó una densidad de corriente de $50 \mu_{\mathrm{Acm}^{-2}}$, mostrando su efectividad en la extracción de iones cloruro de la estructura de akaganeita, principal producto de corrosión del hierro en medio marino. Con estos antecedentes, y debido al alto grado de deterioro de las piezas halladas, se optó por 50 $\mu \mathrm{Acm}^{-2}$ y $1000 \mathrm{~A} \mathrm{Am}^{-2}$ como densidades de corriente a testar.

Así, se fabricaron celdas electrolíticas usando malla de acero galvanizado en caliente $(1 \mathrm{~cm} \times 1 \mathrm{~cm}$ de luz y un grosor de alambre de 1,90 mm), cables de electricidad de hilo de cobre y pinzas de cocodrilo. Se realizaron cuatro baños electrolíticos en $\mathrm{NaOH} 5 \mathrm{M}(2 \% \mathrm{p} / \mathrm{v})$ con idéntico volumen de electrolito (43 I) para cada una de las balas, utilizando agua corriente para el primer baño y agua desionizada para los tres siguientes. Los cambios de baños fueron determinados en función de la estabilidad en los valores de las lecturas de la concentración de $\mathrm{Cl}^{-2}$ en el electrolito. La bala número 1 estuvo sometida a una densidad de 50 
$\mu \mathrm{Acm}^{-2}$ y la bala número 2 a $1000 \mu \mathrm{Acm}^{-2}$. Tras el cálculo del área de la esfera, se estableció un amperaje de 0,03 $\mathrm{A}$ para la bala número 1 y 0,8 A para la número 2. El ensayo tuvo una duración total de 2016 horas, dándose por concluido cuando el valor de la concentración de $\mathrm{Cl}^{-}$se estabilizó por debajo de 50 ppm. Se optó por un control directo sobre el amperaje. Las mediciones de $\mathrm{pH}$ se realizaron diariamente, registrándose valores de entre 13,5

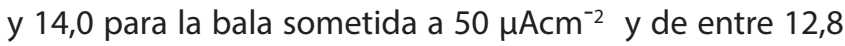
y 13,8 para aquella sometida a $1000 \mu \mathrm{Acm}^{-2}$. La medición del potencial catódico referenciado al electrodo de Ag/ $\mathrm{AgCl}$ se realizó semanalmente, registrándose valores de entre $-0,98$ y $-0,93 \mathrm{~V}$ para la bala sometida a $50 \mu \mathrm{Acm}^{-2}$ y de entre $-0,98$ y $-1,14 \mathrm{~V}$ para la bala sometida a 1000 $\mathrm{AAcm}^{-2}$. La temperatura se mantuvo entre 15 y $22^{\circ} \mathrm{C}$. Debido a la similitud en cuanto a la procedencia y estado de conservación entre las balas y los cañones, se trabajó con la hipótesis de que los resultados obtenidos en este ensayo podrían ser extrapolados al resto de las piezas de gran calibre.

Según muestran los gráficos, el sistema estructurado con $50 \mu \mathrm{Acm}^{-2}$ reveló una mayor eficiencia al conseguir extraer más $\mathrm{Cl}^{-}$a lo largo de la totalidad del tratamiento. Además, se observa que la extracción de dichos iones se produjo fundamentalmente al inicio del primer baño [Gráfico 1].

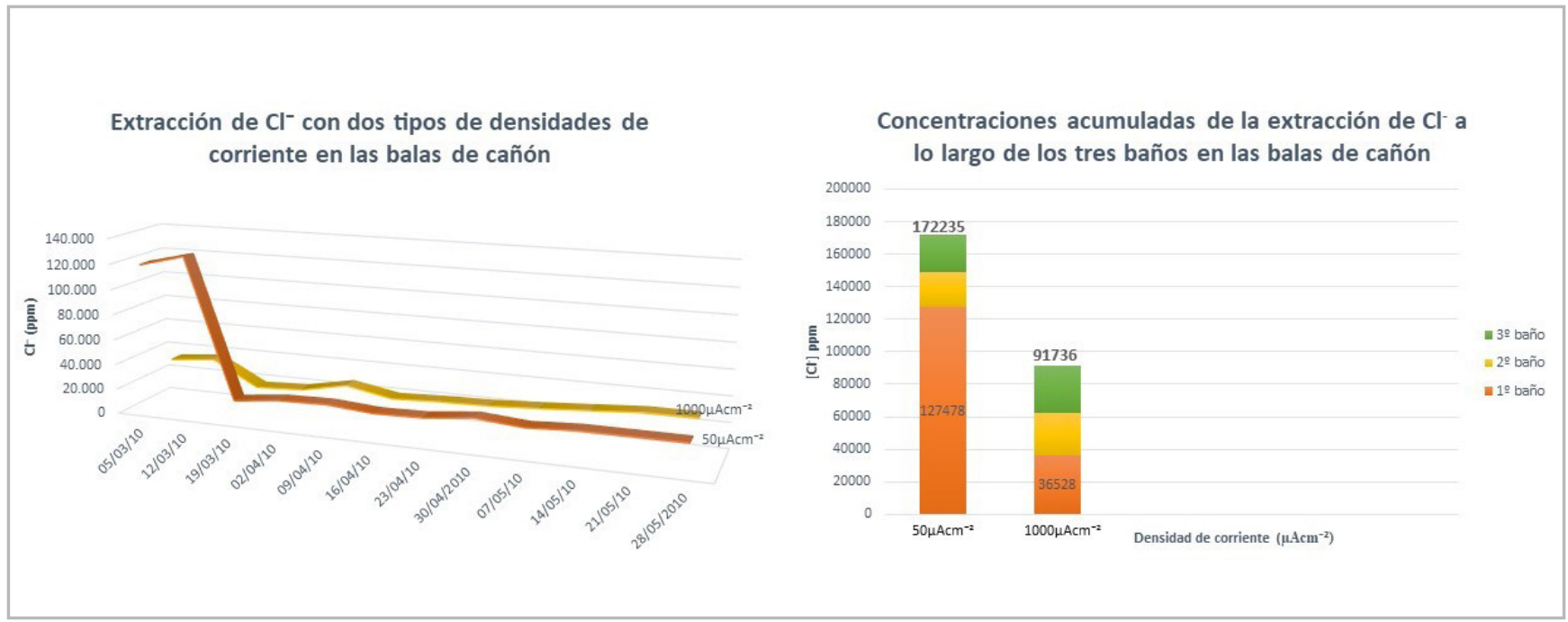

Gráfico 1.- Proceso de extracción de cloruros en las balas de cañón testadas.

Las lecturas en la concentración de $\mathrm{Cl}^{-}$en el $4^{\circ}$ baño dieron resultados "fuera de criterios", indicando que la concentración de cloruros estaba por debajo de los 50 ppm. Asimismo, es interesante destacar que en la bala sometida a $50 \mu \mathrm{Acm}^{-2}$ apenas se observó la aparición de burbujas en su superficie a lo largo de todo el tratamiento. Por su parte, la bala que soportó $1000 \mathrm{\mu Acm}^{-2}$ expulsó menos $\mathrm{Cl}^{-}$, aunque de manera más homogénea, y estuvo burbujeando desde el inicio de forma moderada pero continua debido a una mayor evolución de hidrógeno en su superficie. Considerando tales resultados, se optó finalmente por $50 \mathrm{\mu Acm}^{-2}$ como densidad de corriente más fiable a aplicar en el posterior tratamiento electrolítico de los cañones.

\section{-Tratamiento electrolítico para la extracción de $\mathrm{Cl}^{-}$de los cañones}

A lo largo de la nave se instalaron bases múltiples de electricidad con interruptores, fuentes de alimentación - colocadas sobre repisas cuyos laterales fueron perforados - y ventiladores acoplados a las mismas a fin de evitar el sobrecalentamiento de estas.
Para el montaje de las celdas galvánicas se insertaron en los cañones varillas roscadas de acero inoxidable. Estas se forraron a continuación con tubos de silicona para evitar el contacto con el ánodo de sacrificio. Dicho ánodo se fabricó mediante estructuras tubulares de malla de acero galvanizado en caliente, las cuales se colocaron alrededor de cada cañón [Figura 5]. Finalmente, se soldaron pinzas de cocodrilo a los correspondientes cables de electricidad, quedando cada pieza conectada y activada con parámetros de intensidad y corriente individualizados en función de la superficie de cada cañón.

La densidad de corriente aplicada en los tratamientos electrolíticos de los cañones fue de $50 \mu \mathrm{Acm}^{-2}$. Así, se realizaron un total de tres baños electrolíticos en disolución de $\mathrm{NaOH} 5 \mathrm{M}$, con un amperaje de 1,01-1,32 A, calculado mediante la suma de las áreas de los cilindros del cuerpo principal, los muñones, y la esfera del cascabel. La duración de los baños vino determinada por las lecturas semanales de la concentración de $\mathrm{Cl}^{-}$en el electrolito. Con el fin de mantener el sistema en todo momento dentro del área de protección catódica del diagrama de Pourbaix para el hierro, se realizó un control semanal de $\mathrm{pH}$, temperatura y potencial catódico [Tabla 1]. 

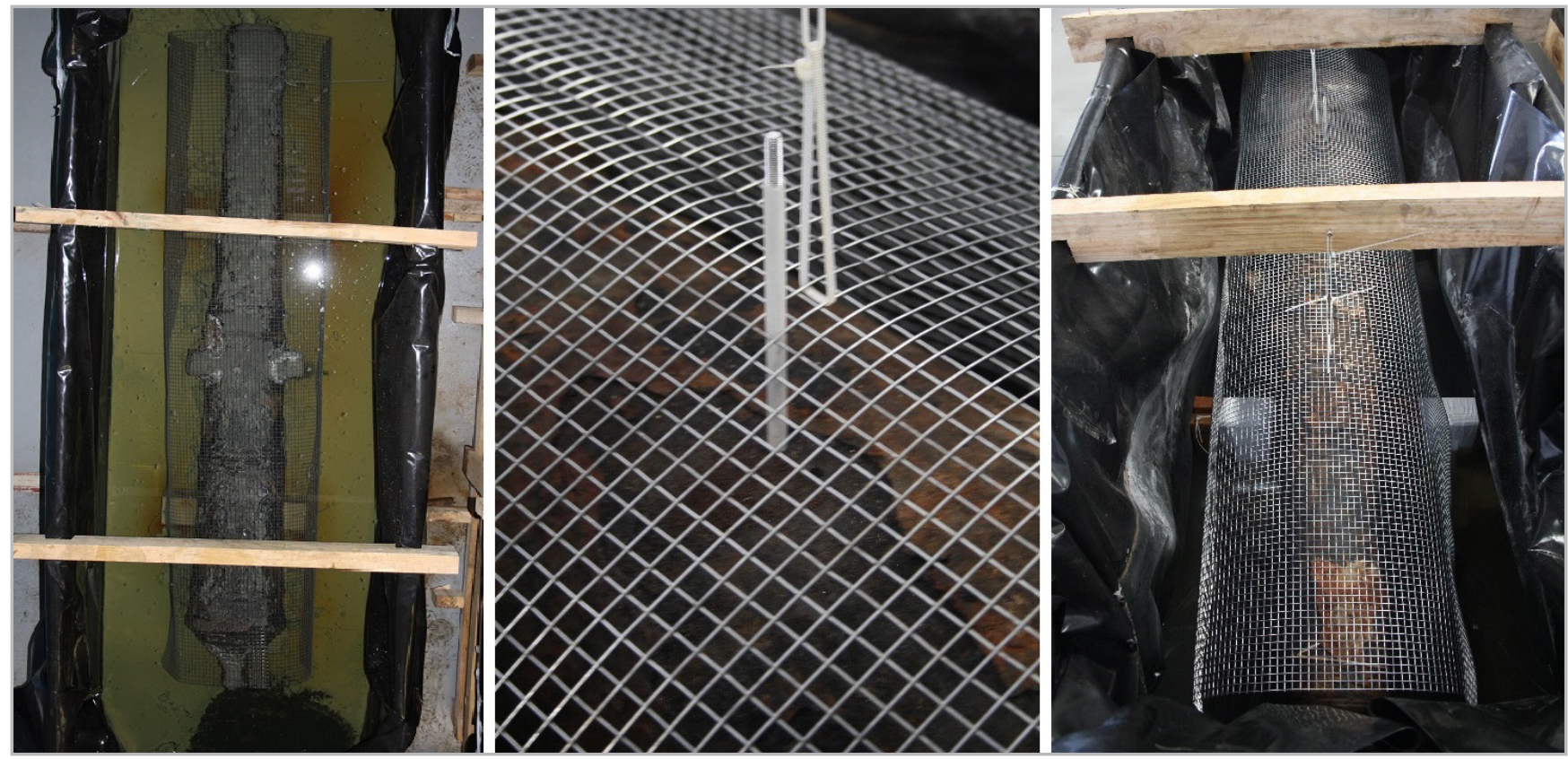

Figura 5.- Cañón depositado en cuba con celda galvánica pre-instalada. (A). Detalle de varilla roscada (B). Celda galvánica (C). Fotografías de archivo de Aula3 AIP S.L.

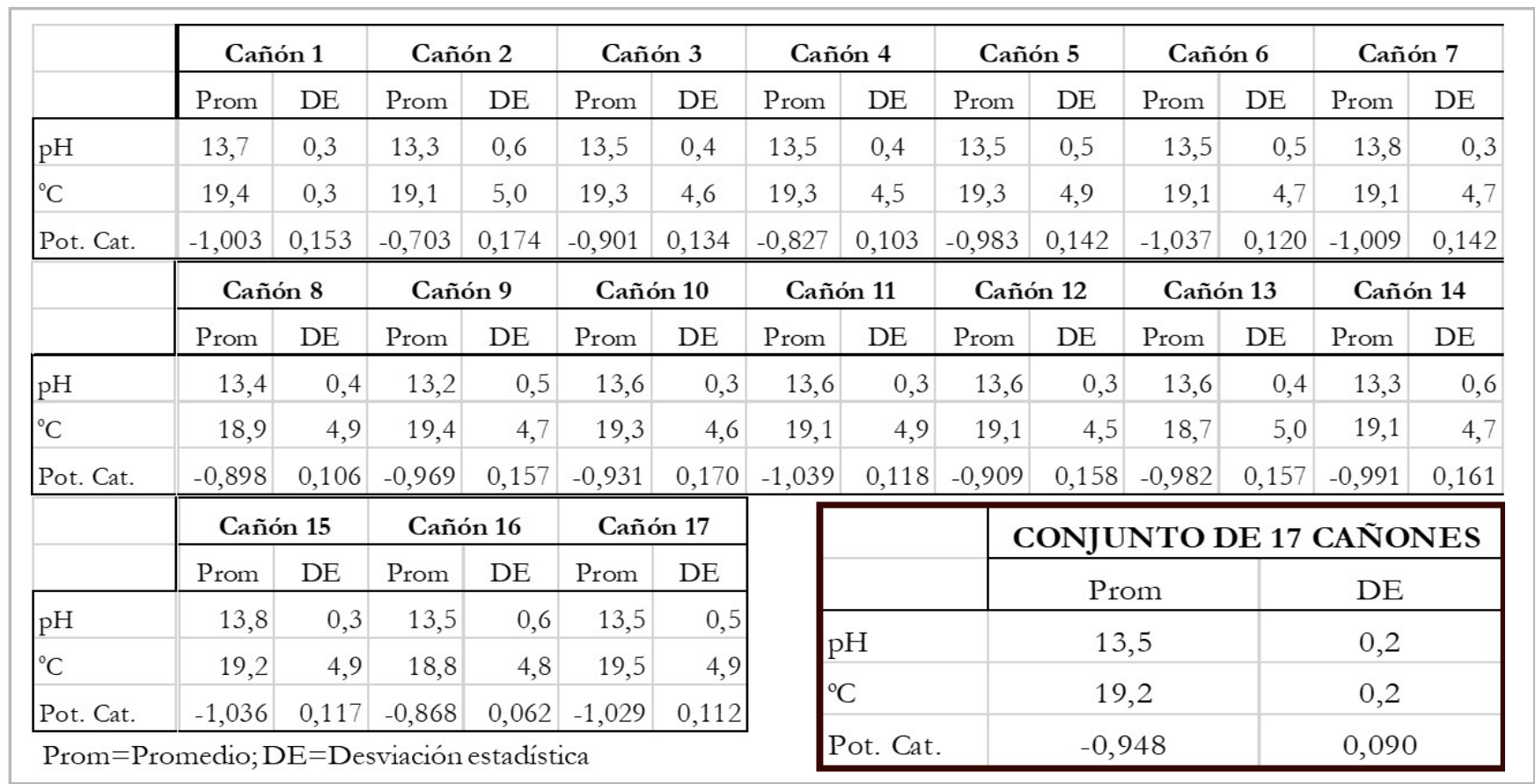

Tabla 1.- Valores registrados de $\mathrm{pH}$, temperatura $\left({ }^{\circ} \mathrm{C}\right)$ y potencial catódico (promedio \pm desviación estándar) durante el proceso de extracción de iones $\mathrm{Cl}^{-}$en los 17 cañones de hierro fundido objetos de tratamiento.

\section{Resultados y Discusión}

- Estabilización inicial mediante baños alcalinos. Reacciones químicas en las piezas

Las cubas fabricadas para la estabilización y tratamiento electrolítico de las piezas mostraron su efectividad; el revestimiento de polietileno permaneció estable ante las disoluciones alcalinas y las estructuras fabricadas en madera resistieron la presión ejercida por el volumen albergado en el interior de las mismas. Tras 24 horas sumergidas en una disolución acuosa de $\mathrm{NaOH} 5 \mathrm{M}, \mathrm{pH} 13,3 \pm 0,6$ y a temperatura ambiente, se observaron afloraciones de distintas morfologías tanto en los cañones como en las balas [Figura 6]. Un análisis elemental de estos productos mediante espectroscopia de energía dispersiva (EDS), llevado a cabo en las instalaciones de la Universidad de Cádiz, reveló que se trataba de óxidos y oxihidróxidos de hierro. 

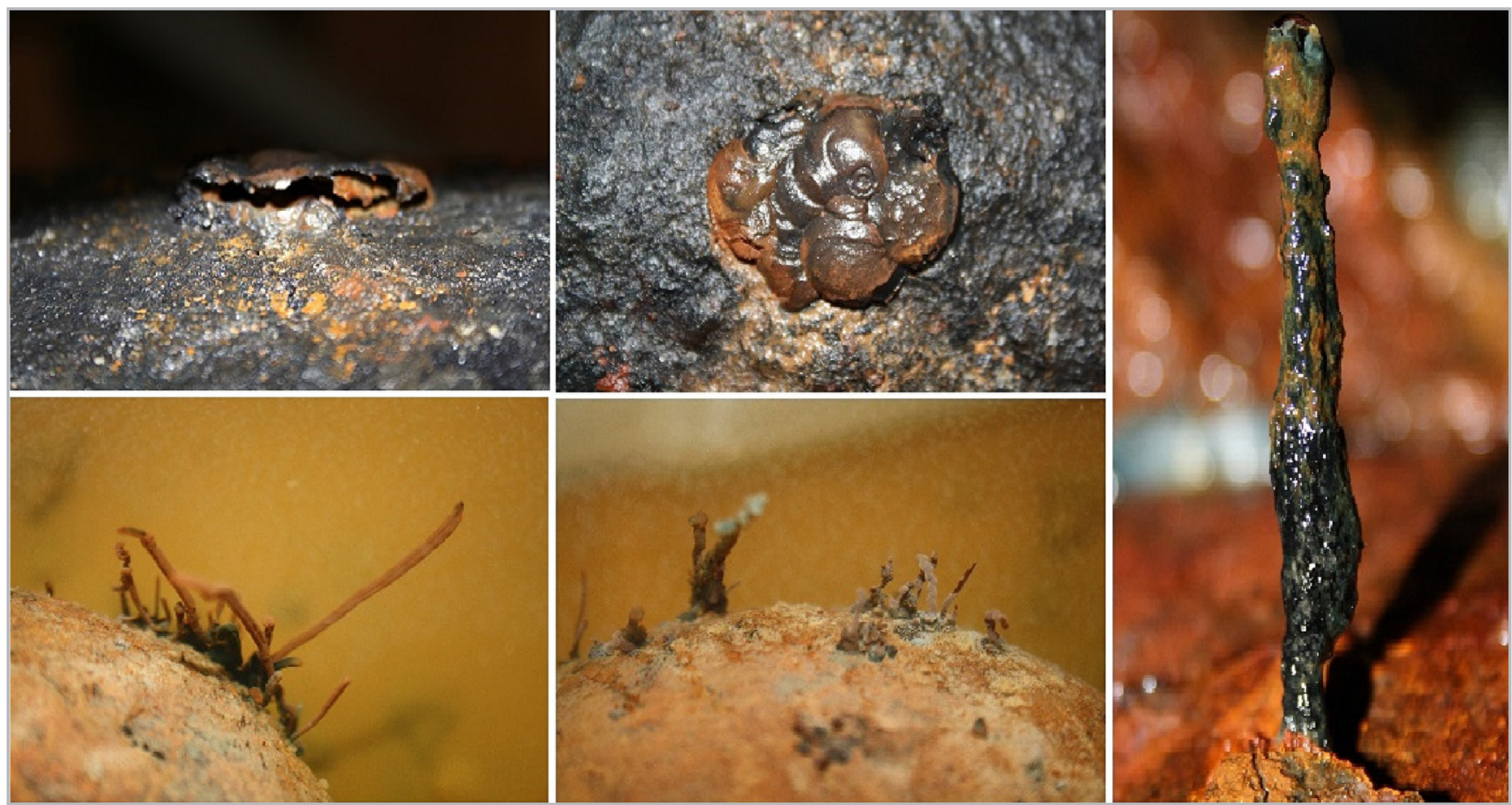

Figura 6.- Afloraciones aparecidas en la superficie de las piezas tras 24 horas sumergidas en una disolución de $\mathrm{NaOH} 5 \mathrm{M}$ en agua corriente y $\mathrm{pH} 13,4 \pm 0,6$. Fotografías de archivo de Aula3 AIP S.L.

Durante la fase de desconcreción de los cañones, realizada fuera de los baños alcalinos, se observaron cambios de color en la superficie del metal que iba quedando expuesto a la atmósfera [Figura 7]. Las reacciones tuvieron una duración aproximada de 20 minutos y provocaron un viraje de color desde el blanco azulado o verde muy claro hasta el naranja, produciéndose únicamente en la superficie del metal que acababa de ser descubierto.

Investigaciones previas han demostrado la formación de hidroxicloruro ferroso $\left(\beta-\mathrm{Fe}_{2}(\mathrm{OH})_{3} \mathrm{Cl}\right)$ como principal producto de corrosión en piezas de hierro sumergidas en medios marinos y anóxicos (Rémazeilles et al. 2009). Este autor también identificó productos con contenidos de azufre (FeS) debido a la presencia de bacterias sulfato-reductoras. En nuestro caso, aún sin información analítica, estudios realizados en sedimentos próximos al hallazgo revelaron igualmente una naturaleza anaerobia y marina de los mismos (Lara-Martín 2005), invitando a pensar que el $\left(\beta-\mathrm{Fe}_{2}(\mathrm{OH})_{3} \mathrm{Cl}\right)$ bien pudiera ser uno de los productos de corrosión iniciales presentes en nuestras piezas.
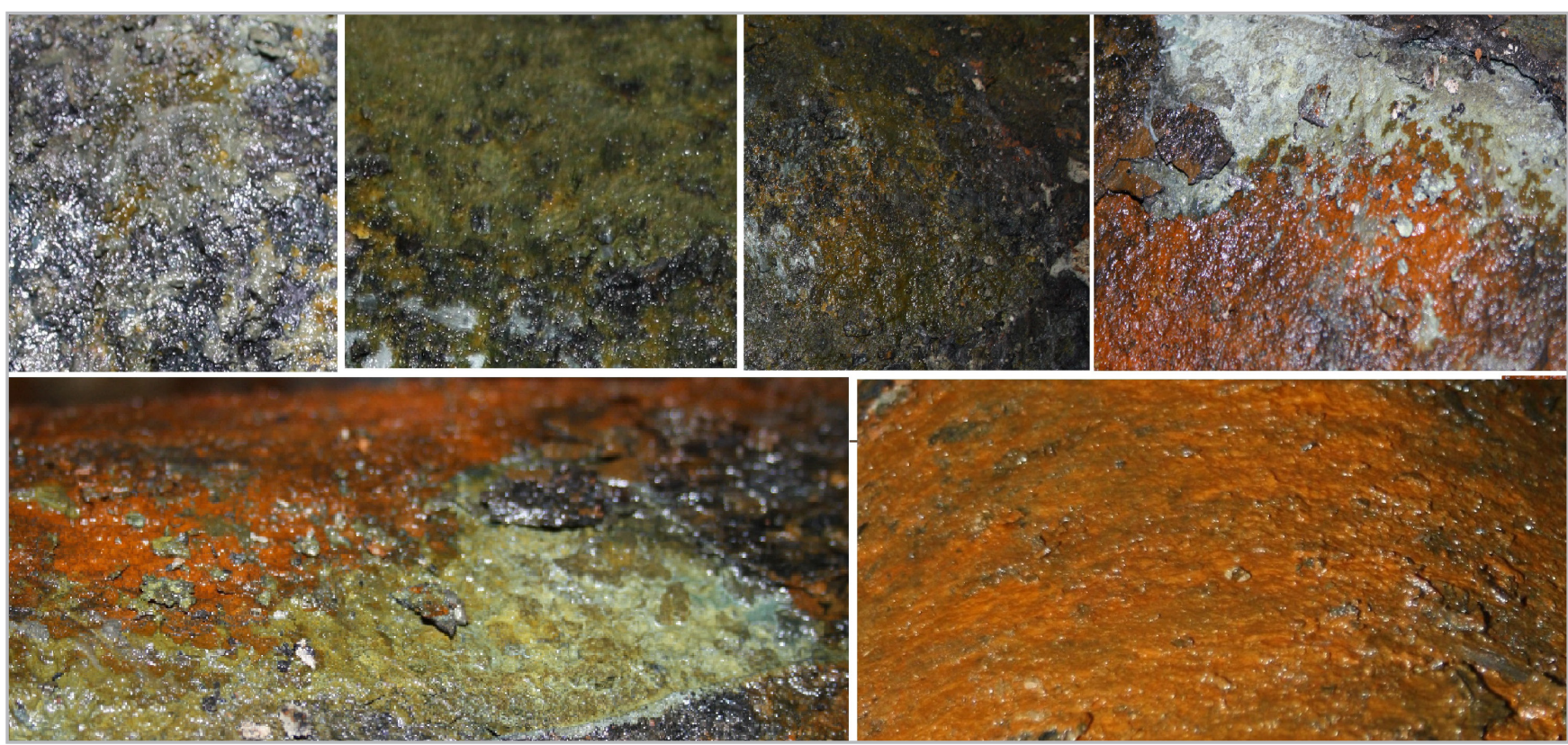

Figura 7.- . Cambios de color en la superficie del metal expuesto a la atmósfera inmediatamente después de su desconcreción. Fotografías tomadas en un periodo de 22 minutos. Ordenadas de arriba abajo y de izquierda a derecha. Fotografías de archivo de Aula3 AIP S.L. 
Por otro lado, las hidroxisales de Fe(II) y Fe(III), comúnmente denominadas "green rust" (GR) (Bernal et al. 1959), son hidróxidos muy reactivos. Estudiados especialmente en el área de la corrosión, se puede distinguir entre GR1 formado generalmente en presencia de $\mathrm{Cl}^{-}$y $\mathrm{CO}_{3}-$ y GR2, formado en presencia de aniones como el $\mathrm{SO}_{4}$ (Génin et al. 2006). Varios autores han identificado la formación de $\mathrm{GR} 1\left(\mathrm{SO}_{3}{ }^{2-}\right)$ y $\mathrm{GR} 2\left(\mathrm{SO}_{4}{ }^{2-}\right)$ en piezas de origen marino procedentes de contextos anaeróbicos, así como la presencia localizada de $\mathrm{GR} 1\left(\mathrm{Cl}^{\prime}\right)$, al introducir las piezas de origen marino en medios alcalinos, sea por la oxidación de $\mathrm{Fe}(\mathrm{OH})_{2}$ o $\beta-\mathrm{Fe}_{2}(\mathrm{OH})_{3} \mathrm{Cl}$, o bien por su precipitación directa en presencia de $\mathrm{Fe}^{3+}$ y $\mathrm{Fe}^{2+}$ (Génin et al. 1993; Olowe et al. 1989; Stampfl et al. 1969). Asimismo, se describe como una práctica común la oxidación, en presencia de aire, de hidróxidos ferrosos $\mathrm{Fe}(\mathrm{OH})_{2}$-obtenidos mediante la inmersión de sales ferrosas en disoluciones de $\mathrm{NaOH}$ y combinados con iones de $\mathrm{Cl}^{-}, \mathrm{SO}_{4}{ }^{2-} \mathrm{o} \mathrm{CO}_{3}{ }^{2-}$ - para obtener óxido verde sintético (GRs), reconocido como un producto intermedio durante el proceso de oxidación del hierro en medios acuosos (Génin et al. 1998; Refait et al. 1997).

A este respecto, una investigación reciente realizada en piezas de hierro de procedencia marina ha estudiado el efecto del $\mathrm{O}_{2}$ disuelto en disoluciones alcalinas aireadas y sin airear, identificando los productos de corrosión resultantes durante los tratamientos de estabilización (Kergourlay et al. 2018). Para ello, el autor monitorizó in situ la evolución de las capas de corrosión compuestas por $\beta-\mathrm{Fe}_{2}(\mathrm{OH})_{3} \mathrm{Cl}$ de las piezas, las cuales habían sido halladas en contextos anaeróbicos y sumergidas tras su extracción en una disolución de $\mathrm{NaOH} 5 \mathrm{M}, \mathrm{pH}$ de 13,5 a temperatura ambiente. Los resultados, expuestos mediante mapas realizados con micro-difracción de rayos $X(\mu \mathrm{XRD})$, en periodos de entre 23 y 56 minutos, mostraron la transformación del $\beta-\mathrm{Fe}_{2}(\mathrm{OH})_{3} \mathrm{Cl}$ en $\mathrm{Fe}(\mathrm{OH})_{2}$ y $\mathrm{Fe}_{3} \mathrm{O}_{4}$ en medios alcalinos no aireados, así como la formación de estos mismos óxidos e hidróxidos junto con la aparición local de $\mathrm{GR} 1\left(\mathrm{Cl}^{-}\right)$en disoluciones alcalinas aireadas.

Por tanto, atendiendo a la naturaleza de las piezas tratadas en nuestro trabajo (hierro arqueológico), el contexto en el que fueron halladas (medio marino anaeróbico) y las condiciones de temperatura y alcalinidad a las que fueron sometidas durante su pasivación y desconcreción, sería razonable considerar que tanto las afloraciones mostradas en la figura 6, como las alteraciones de color recogidas por la figura 7, pudieran ser productos derivados de la evolución de las capas de corrosión compuestas por $\beta-\mathrm{Fe}_{2}(\mathrm{OH})_{3} \mathrm{Cl}$ en medios alcalinos. Estas imágenes resultan de especial interés y originalidad debido a la fugacidad de tales reacciones químicas. En todo caso, sería recomendable abordar estudios específicos a fin de contrastar la hipótesis expuesta.

\section{- Herramientas específicas, técnica de estabilización de ur- gencia y tratamiento electrolítico}

Las bases de trabajo giratorias no solo facilitaron la ergonomía de los técnicos responsables de la desconcreción de los cañones, sino que agilizaron el proceso en sí mismo. Estas bases resistieron con robustez las cargas y vibraciones a las que fueron sometidas. Las ruedas que acogían las piezas facilitaron tanto el apoyo como el giro de los cañones, no causándoles daño alguno independientemente de la longitud y anchura de los mismos. Tras la limpieza mecánica de los cañones no se observaron registros documentales en sus superficies.

La barrena de alta presión consiguió realizar una limpieza precisa de las ánimas de los cañones, sin dejar marcas en las mismas; como muestra del óptimo rendimiento del sistema, el CAS solicitó la colaboración de la empresa para la limpieza de una pieza similar extraída durante una campaña del Proyecto Trafalgar. Dicha colaboración tuvo como resultado la recuperación de un saquete de metralla compuesto por 20 balas de pequeño calibre (Bethencourt y Zambrano 2011).

La técnica de estabilización de urgencia mantuvo las piezas empapadas en la disolución alcalina a lo largo de tres días. Este resultado es especialmente interesante ya que revela la efectividad de la misma en condiciones de temperatura ambiental media-alta, validando así su potencial aplicación a pie de obra en piezas de gran envergadura de origen marino. En un trabajo reciente se ha planteado como novedad la aplicación de un procedimiento similar al nuestro para hierros inamovibles consistente en la aplicación de $\mathrm{NaOH}$ mediante envolturas de material absorbente (Veneranda 2021), utilizado normalmente para la extracción de iones cloruro en piedra (Pozo A., J. S. et al. 2016), demostrando la originalidad de la técnica aplicada en su momento en nuestras piezas.

Los tratamientos electrolíticos de los cañones resultaron efectivos y tuvieron una duración de entre 9 y 11 meses, dándose por concluidos cuando las lecturas de la concentración de $\mathrm{Cl}^{-}$se estabilizaron en valores de $80 \pm 20$ ppm.

\section{- Fin del tratamiento y divulgación}

Las fases finales del tratamiento de restauración de las piezas no son objeto de este trabajo, habiendo sido realizadas por un equipo de profesionales diferente al que presenta este artículo. Según comunicación personal, las piezas se neutralizaron con baños de agua desionizada y se secaron mediante la aplicación de acetona, quedando a continuación expuestas al aire. Posteriormente, se aplicó una disolución de ácido tánico en alcohol metílico al 3\% (p/v). Por último, se aplicó una capa protectora de Incral 44 mediante pulverizado.

La restauración de este grupo de piezas arqueológicas y su gestión posterior generaron el interés popular, que se evidenció mediante su divulgación a través de titulares en prensa local y regional, así como en los informativos de la cadena de televisión regional en Andalucía [Figura 8]. 


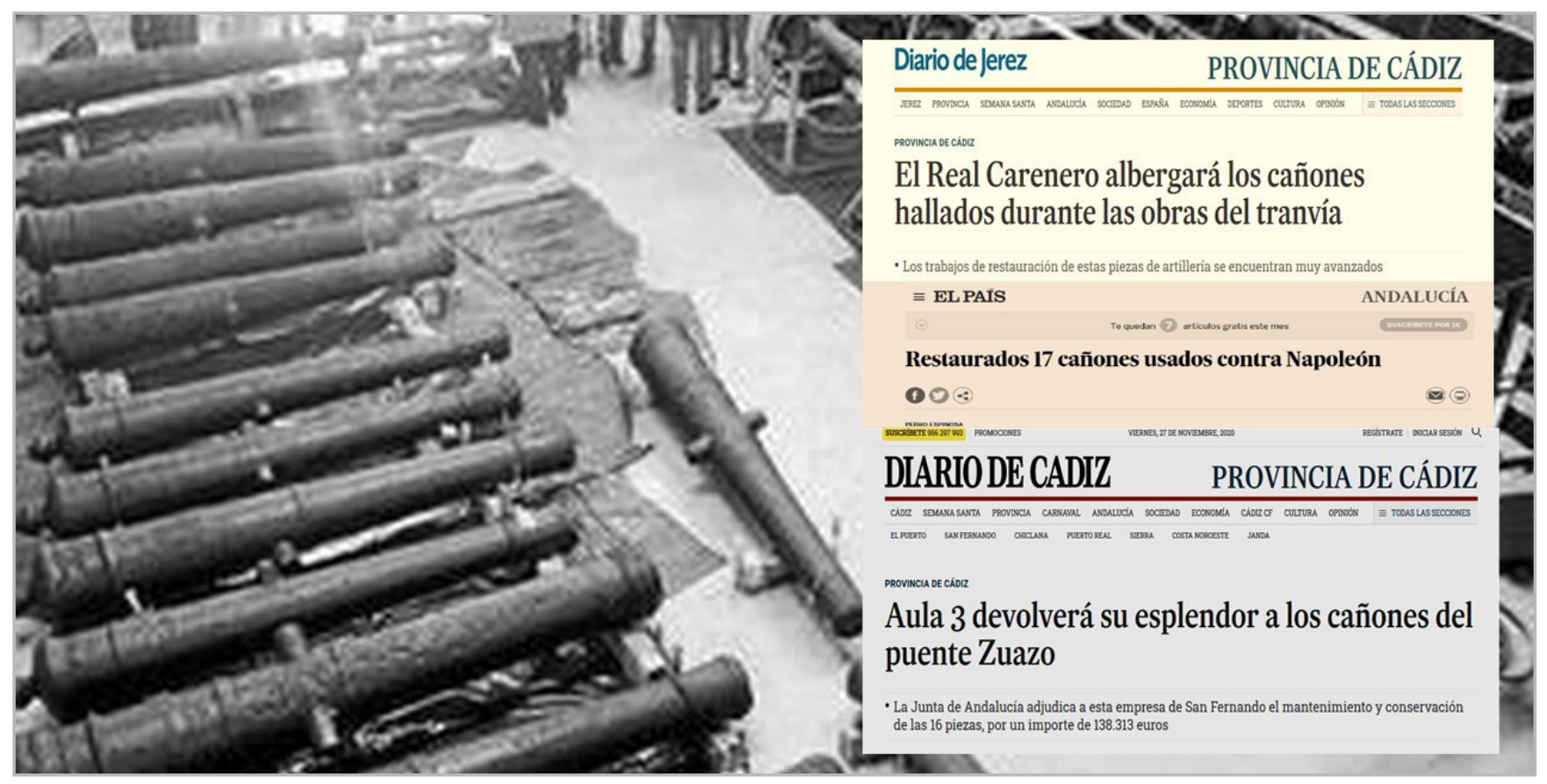

Figura 8.- Fotografía de archivo de los cañones recién restaurados extraída de la edición del 9 de junio de 2011 del Diario de Jerez (fondo). Repercusión mediática (derecha).

\section{Conclusiones y consideraciones finales}

Por la envergadura de las tareas realizadas, el trabajo descrito supone un hito en el tratamiento simultáneo de conservación de piezas histórico-arqueológicas, de artillería pesada de procedencia subacuática. Las cubas y las herramientas de bajo coste específicamente desarrolladas -barrena de alta precisión y bases de trabajo giratorias-, así como la técnica de estabilización de urgencia utilizada, demostraron su efectividad a lo largo del tratamiento agilizando las tareas realizadas. Además, un estudio comparativo previo, realizado en piezas procedentes del mismo hallazgo, permitió comprobar la mayor eficiencia de $50 \mu \mathrm{Acm}^{-2}$ frente a $1000 \mu \mathrm{A} \mathrm{cm}^{-2}$ como densidad de corriente a aplicar en el posterior tratamiento electrolítico. Desde nuestro punto de vista, el conjunto de tales singularidades, enmarcado en un contexto de bajo presupuesto, convierten las labores de conservación descritas en una referencia para futuras actuaciones homólogas.

\section{Materiales y proveedores}

Medidor pH modelo Phep 4. HANNA INSTRUMENTS S.L.

Titrador SALT-matic 23. CRISON Instruments, SA.

Desmineralizador modelo Lunik 2002. Termómetro modelo Key. Micro-cincel Modelo CTS 178. Vibro-incisor Modelo CTS F1. Fuente de alimentación Tti CPX200 DUAL. En C.T.S. ESPAÑA.

Fuentes de alimentación ajustables HQ Power PS1503SB de 0-15V y 3A. https://www.velleman.eu
Electrodo de referencia CRISON $52-40 \mathrm{Ag} / \mathrm{AgCl}$. CRISON Instruments, SA.

\section{Agradecimientos}

A todas y cada una de las personas que formaron parte del equipo de trabajo, a los revisores anónimos por la aportación de perspectiva que sirvió para mejorar el trabajo y al Laboratorio de Estudios y Conservación del Patrimonio Histórico (LEC-PH) de la UCA, financiado por FEDER-MICIN EQC2018-004947-P.

\section{Referencias}

GOBIERNO DE MÉXICO, INSTITUTO NACIONAL DE ANTROPOLOGÍA E HISTORIA (INAH). "Aplican tratamiento a cañones centenarios de Campeche". https://inah.gob.mx/boletines/1065-aplicantratamiento-a-canones-centenarios-de-campeche

BERNAL, J.D., DASGUPTA, D., RMACKAY, A.L. (1959). "The oxides and hydroxides of iron and their structural interrelations". En Clay Miner. Bull, 4: 15-30.

BERTHOLON, R AND RELIER C. (1990). “Les métaux archéologiques". En La conservation en archéologie. Méthodes et pratique de la conservation-restauration des vestiges archéologiques, Masson, Paris, France, 163-22.

BERTHOLON, R. (2001). “Nettoyage stabilisation de la corrosión per électrolyse". En La conservation des métaux, Volfovsky, C. (Coord.) París. CNRS EDITIONS, 83-101. 
BETHENCOURT, M Y ZAMBRANO, L. (2011). "Análisis de cloruros en la zona grafitizada de un cañón de hierro procedente del pecio Bucentaure (La Caleta, Cádiz) tratado mediante polarización catódica de baja intensidad". En IV Congreso Latinoamericano de Conservación y Restauración de Metal, Madrid, 256-270. https://doi. org/10.13140/2.1.4906.7849

BURSHNEVA, S. AND SMIRNOVA, N., (2010). "Archaeological Iron Conservation Colloquium" -Extended Abstracts Session 3: Alkaline Chloride Extraction, State Academy of Art and Design, Extended Abstracts, 24th to 26th June Stuttgart, Germany.

CARLIN, W., KEITH, D. AND RODRÍGUEZ, J. (2001). "Less is more: measure of chloride removal rate from wrought iron artifacts during electrolysis". En Studies in Conservation, 46: 68-76.

COELHO, J.C. (2010). "Estudo da eficiência de técnicas electroquímicas na remoção de cloretos em amostras de uma bala de canhão proveniente de um naufrágio do séc. XVIII", Dissertações de Mestrado, Repositório da Universidade de Lisboa, Comunidades \& Colecções, Faculdade de Ciências (FC).

COELHO, J.C., OLIVEIRA, C.M., CARVALHO M. D. AND FONSECA I.T.E. (2014). "The efficiency of electrochemical methods for the removal of chloride ions from iron marine archaeological objects: A comparative study". En Materials and Corrosion, 65(1): 38-44. https://doi.org/10.1002/maco.201206584

CORNELL, R. AND GIOVANOLI, R. (1986). "Factors that govern the formation of multi-domainic goethites". En Clays and Clay Minerals, 34(5): 557-564. https://doi.org/10.1346/CCMN.1986.0340509

DEGRIGNY, A., (2010). "Use of electrochemical techniques for the conservation of metal artefacts: A review", En Journal of Solid State Electrochemistry 14(3):353-361. https://doi.org/10.1007/s10008$\underline{009-0896-0}$

DOMÉNECH-CARBÓ A., DOMÉNECH-CARBÓ M.T. AND COSTA V. (2009). "Electrochemical methods in Archaeometry, Conservation and Restoration", En Series: Monograph in Electrochemistry (Ed. F. Scholz), Springer-Verlag Berlin Heidelberg, Berlin, 166.

GÉNIN J.M.R., BOURRIÉ G., TROLARD F., ABDELMOULA M., JAFFREZIC A., REFAIT P., MAITRE V., HUMBERT B., HERBILLON A. (1998). "Thermodynamic equilibria in aqueous suspensions of synthetic and natural $\mathrm{Fe}(\mathrm{II})-\mathrm{Fe}$ (III) green rusts: occurrences of the mineral in hydromorphic soils". En Environ Sci. Technol, 32: 1058-1068. https:// doi.org/10.1021/es970547m

GÉNIN, J.M.R.; OLOWE, A. A.; RÉSIAK, B.; BENBOUZID-ROLLET, N. D.; CONFENTE, M.; PRIEUR, D. (1993). "Marine corrosion of stainless steels: chlorination, and microbial effects". En European Federation Corrosion Series; The Institute of Materials: London, 10:162-166.

GÉNIN J.M.R., ABDELMOULA, M., RUBY, C AND UPADHYAY C. (2006). "Speciation of iron; characterisation and structure of green rusts and Fell-IIl oxyhydroxycarbonate fougerite". En C. R. Geoscience 338: 402-419. https://doi.org/10.1007/s10751-011-0500-8
GIL, M.L.A., SANTOS, A., BETHENCOURT, M., GARCÍA, T., FERNÁNDEZBASTERO, S., VELO, A., GAGO-DUPOR L. (2003). "Use of X-ray and other techniques to analyse the phase transformation induced in archaeological cast iron after its stabilisation by the electrolytic method". En Analytica Chimica Acta, 494: 245-254. https://doi.org/ 10.1016/j.aca.2003.08.012

HAMILTON, D. (1997). "Basic Methods of Conserving Underwater Archaeological Material Culture". Nautical Archaeology Program, Department of Anthropology, Texas, A\&M University.

KERGOURLAYA F., RÉGUERB S., NEFFA D., FOYA E., PICCAB F.E., SAHEBC M., HUSTACHEBS., MIRAMBETD F., DILLMANNA P. (2018). “Stabilization treatment of cultural heritage artefacts: In situ monitoring of marine iron objects dechlorinated in alkali solution". En Corrosion Science, 132: 21-34. https://doi.org/10.1016/j.corsci.2017.12.028

LARA-MARTÍN P.A., GÓMEZ-PARRA A., PETROVIC M., BARCELÓ D., GONZÁLEZ-MAZO E. (2005). "Distribution of organic pollutants in coastal sediments of Cádiz Bay (SW Spain)". En Ciencias Marinas 31(1B): 203-212. https://doi.org/10.7773/cm.v31i12.95

MINISTERIO ESPAÑOL DE CULTURA Y DEPORTE. “Proyecto Nuestra Señora de las Mercedes". http://www.culturaydeporte.gob.es/ mnarqua/investigacion/proyectos/nsm.html [Consulta: 05/11/2019].

OLOWE, A. A.; BAUER, PH.; GÉNIN, J.-M. R.; GUE'ZENNEC, J. (1989). "Moessbauer Effect Evidence of the Existence of Green Rust 2 Transient Compound from Bacterial Corrosion in Marine Sediments". En Corrosion, 45 (3): 229-235. https://doi.org/10.5006/1.3577848

PLENDERLEITH, H. J. (1956). The Conservation of Antiquities and Works of Art. London. Oxford University Press.

POZO A., J. S.; RIVAS, T.; LÓPEZ, A. J.; FIORUCCI, M. P.; RAMIL, A. (2016). "Effectiveness of granite cleaning procedures in cultural heritage: A review". Sci. Total Environ, 571: 1017-1028. https://doi.org/ 10.1016/j.scitotenv.2016.07.090

RAMOS GIL, A. (2015).“Recuperación de 16 cañones del siglo XVIII, y su puesta en valor en las murallas de Cádiz". En Actas del II Congreso de Conservación y Restauración del Patrimonio Metálico. MetalEspaña 2015. Real Casa de Moneda, Segovia, 200-205.

REFAIT, PH.; GÉNIN, J. M. R. (1997). "Mechanisms of oxidation of $\mathrm{Ni}$ (II)-Fe(II) hydroxides in chloride-containing aqueous media: role of the pyroaurite-type Ni-Fe hydroxychlorides" En Clay Minerals 32(4): 597-613

RÉMAZEILLES C., NEFF D., KERGOURLAY F., FOY E., CONFORTO E., GUILMINOT E., REGUER S., REFAIT PH., DILLMANN PH. (2009). "Mechanisms of long-term anaerobic corrosion of iron archaeological artefacts in seawater". En Corrosion Science, 51: 29322941. https://doi.org/10.1016/j.corsci.2009.08.022

RIMMER, M., WATKINSON, D. AND WANG, Q. (2013). “The impact of chloride desalination on the corrosion rate of archaeological iron". En Studies in Conservation, 58(4): 326-337. https://doi.org/ $\underline{10.1179 / 2047058412 Y .0000000068}$ 
SCMUTZLER B. AND EBINGER-RIST, B.N. (2008). "The conservation of iron objects in archaeological preservation - Application and further development of alkaline sulphite method for conservation of large quantities of iron finds". En Materials and Corrision, 59(3), 248-245. https://doi.org/10.1002/maco.200804109

SELWYN, L. (2004). "Overview of archaeological iron: the corrosion problem, key factors affecting treatment, and gaps in current knowledge", Metal 04: Proceedings of the International Conference on Metals Conservation, Canberra, Australia, 4-8 October 2004, 294-306.

STAMPFL, P. P. (1969). "Ein basisches eisen-II-III-karbonat in rost". En Corrosion Science, 9:185-187. https://doi.org/10.1016/S0010938X(69)80029-6

UNESCO (2001). Convención de la Unesco. La Protección del Patrimonio Cultural Subacuático. París. http://portal.unesco.org/es/ ev.php-URL ID=13520\&URL DO=DO TOPIC\&URL SECTION=201. html [Consulta: 08/10/2019].

VENERANDA, M., PRIETO-TABOADA, N., CARRERO, J.A. COSTANTINI, I., LARRAÑAGA, A., CASTRO, K., ARANA G. AND MADARIAGA, J.M. (2021). “Development of a novel method for the in-situ dechlorination of immovable iron elements: optimization of $\mathrm{Cl}$ - extraction yield through experimental design". En Scientific Reports , 11:10789. https:// doi.org/10.1038/s41598-021-90006-y

WANG, Q., (2007). An Investigation of Deterioration of Archaeological Iron". En Studies in Conservation, 52(2: 125-134. https://doi.org/ $\underline{10.1179 / \text { sic. } 2007.52 .2 .125}$

WANG, Z., XU, C., CAO, X., AND XU, B. (2007). "The Morphology, Phase Composition and Effect of Corrosion Product on Simulated Archaeological Iron". En Chinese Journal of Chemical Engineering, 15(3): 433-438. https://doi.org/10.1016/S1004-9541(07)60104-9

WATKINSON, D. AND A. AL-ZAHRANI, A. (2008). "Towards quantified assessment of aqueous chloride extraction methods for archaeological iron: De-oxygenated treatment environments". En The Conservator, 31: 75-86. https://doi.org/10.1080/01410096.2008.9995234

\section{Autor/es}

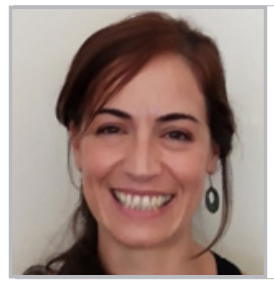

\section{Inmaculada Sánchez Pedreño}

puracsp@gmail.com

Aula3 Actuaciones Integrales sobre el Patrimonio S.L.

https://orcid.org/0000-0003-3670-8820

Inmaculada Sánchez Pedreño es Licenciada en BBAA por la Universidad de Sevilla y Master en Patrimonio Histórico Arqueológico por la Universidad de Cádiz. Realizó su proyecto de master titulado: "La Restauración de Bienes Culturales Subacuáticos: Técnicas Básicas para Madera, Hierro y Bronce". Desde el año 2005 hasta el 2012 se ha formado realizando cursos dirigidos de manera específica a la conservación y restauración del Patrimonio Cultural Subacuático en instituciones como el Centro de Arqueología Subacuática de
Andalucía (CAS) y el Centre d'Arqueologia Subaquàtica de Catalunya. Ha asistido a jornadas de Museología en el ARQUA y participado en cursos de postgrado como el VIII Postgraduate Course "Silicon Plastination Technique (S10)", realizado por la Universidad de Murcia. Fue becada por el CAS para participar en el proyecto del programa Interreg ARCHEOMED en el año 2008. Su experiencia profesional ha sido desarrollada como restauradora en el Museo Naval de San Fernando en Cádiz durante periodos comprendidos entre el 2006 y el 2013 y como directora y coordinadora del departamento de restauración de Aula3 AIP S.L. entre los años 2009 y 2011. Participó como ponente en el congreso MetalEspaña2020 y actualmente trabaja como profesional independiente y colabora con la Facultad de Letras de la Universidad de Oporto (FLUP) y con la Bridge Collection del WOW (World of Wine) en Vila Nova de Gaia, Portugal.

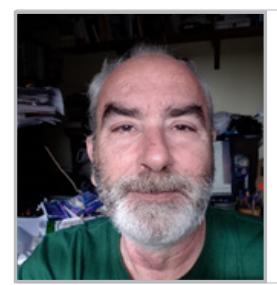

Ignacio Salas Pardo de Donlebún salasignacio@gmail.com Aula3 Actuaciones Integrales sobre el Patrimonio S.L.

Ignacio Salas Pardo de Donlebún es Licenciado en CC de la Información por la Universidad Complutense de Madrid y Master en Patrimonio Histórico Arqueológico por la Universidad de Cádiz. Socio fundador de la empresa Aula3 Actuaciones Integrales sobre el Patrimonio, ha realizado el curso Restauración de Material Arqueológico Subacuático por el Centre d'Arqueologia Subaquàtica de Catalunya del Museo d'Arqueologia de Catalunya, el curso "Construcción Naval: su registro Arqueológico", realizado por el Instituto Andaluz de Patrimonio y el VIII Postgraduate Course "Silicon Plastination Technique (S10)", realizado por la Universidad de Murcia en el año 2009. Como periodista, ha acompañado los acontecimientos relacionados con la Arqueología Subacuática en España desde el año 2000. Actualmente trabaja para los informativos de Canal Sur en C/ Carpinteros de Ribera, 2, CP 11012 Cádiz.

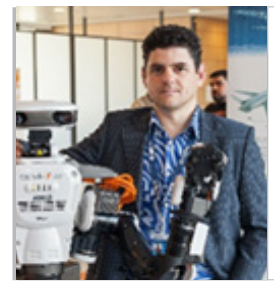

Juan Francisco García Amado

garcia_amado@hotmail.com

Airbus Operations

Juan Francisco García Amado es Titulado en Ingeniería Mecánica por la Universidad de Cádiz. Especialista en construcción de maquinaria Con formación especializada en metrología industrial trabajó durante 8 años en taller de mecanizado de precisión diseñando mejoras en maquinaria industrial para General Motors. Cuenta con 4 años de experiencia en inspección de utillajes aeronáuticos. Apasionado de la arqueología subacuática, ha colaborado asesorando y diseñando maquinaria específica en actuaciones dirigidas a la conservación y restauración del PCS realizadas por la empresa Aula3 AIP S.L. entre los años 2009 y 2011. Hace 15 años que trabaja en automatización de procesos y robótica en Airbus Operations: Calle Portugal, 9. 11519 Puerto Real, Cadiz, Spain. 


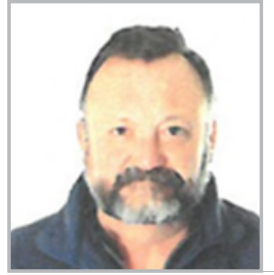

\section{Santos García Trigo}

sgtrigo@gmail.com

Aula3 Actuaciones Integrales sobre el

Patrimonio S.L.
Santos García Trigo es Licenciado en Derecho. Especialista en Derecho Medioambiental por la Universidad de Educación a Distancia (UNED) y Master en Patrimonio Histórico Arqueológico por la Universidad de Cádiz. Apasionado de la arqueología subacuática ha sido socio fundador de la empresa Aula3 Actuaciones Integrales sobre el Patrimonio y redactando del proyecto de Reglamento de Arqueología Subacuática de la Republica de Cabo Verde, encargado por la Agencia Española de Cooperación Internacional, en colaboración con el CAS en el año 2009. Colaborador habitual y asesor del departamento de restauración de Aula3 AIP S.L. Actualmente es delegado en Delegación del ISFAS en Soria. Rda/ Eloy Sanz Villa 8. 42003 Soria.

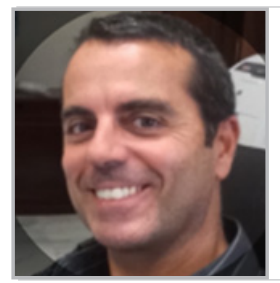

\section{Manuel Bethencourt Núñez}

manuel.bethencourt@uca.es

Universidad en el Departamento de Ciencia de los Materiales e Ingeniería Metalúrgica y Química Inorgánica de la Universidad de Cádiz https://orcid.org/0000-0002-0488-7097

Manuel Bethencourt Núñez es Catedrático de Universidad en el Departamento de Ciencia de los Materiales e Ingeniería Metalúrgica y Química Inorgánica de la Universidad de Cádiz. Su investigación se ha circunscrito en general al estudio de los procesos de corrosión de aleaciones metálicas en medio marino, al desarrollo de métodos de protección de bajo impacto ambiental y a estudios arqueométricos. Otras líneas de investigación han sido el desarrollo de nuevas técnicas electroquímicas para el estudio de los procesos de corrosión, especialmente el Ruido Electroquímico, y el desarrollo de recubrimientos de oxinitruros de circonio. Ha publicado un total de 103 trabajos. De estos, un número importante están indexados con índice de calidad relativa: 69 en JCR, 77 en Web of Science, u 80 en Scopus. 18 son artículos en publicaciones científicas con índice de calidad relativa y 16 son libros o capítulos de libros en investigación. Su índice h es 24. Ha presentado 126 trabajos presentados en 72 congresos, la mayoría publicados en libros con ISBN, y es autor de 2 Patentes Internacionales y 2 Registros de la Propiedad Intelectual (software). Investigador responsable de 7 proyectos de investigación ( 1 europeo, 5 nacionales y 1 autonómico), numerosos contratos de investigación para la industria y tres solicitudes de grandes infraestructuras científicas en programas de incentivos FEDER. También ha participado como investigador en los equipos de 15 proyectos de investigación nacionales, regionales y europeos, y en 19 contratos de investigación. Ha dirigido 6 Tesis Doctorales, 9 Trabajos Fin de Máster, 3 Tesis de Licenciatura, y 2 Proyectos Finales de Ingeniería. Actualmente dispone de 4 tramos o sexenios de investigación y 1 de transferencia. Ha sido Vicerrector de Investigación y Transferencia de la UCA (2011-2015).
Artículo enviado el 21/02/2021 Artículo aceptado el 16/12/2021

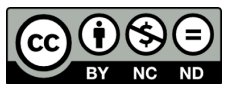

https://doi.org/10.37558/gec.v21i1.970 